\title{
Approaching the Direct Object Pronouns: How Much Grammatical Form Is Necessary in Instruction?*
}

\author{
Melanie L. D’Amico \\ Department of Languages, Literatures \& Linguistics, Indiana State University, Terre Haute, USA \\ Email: mdamico@indstate.edu
}

Received July $24^{\text {th }}, 2013$; revised August $25^{\text {th }}, 2013$; accepted September $5^{\text {th }}, 2013$

\begin{abstract}
Copyright (C) 2013 Melanie L. D’Amico. This is an open access article distributed under the Creative Commons Attribution License, which permits unrestricted use, distribution, and reproduction in any medium, provided the original work is properly cited.
\end{abstract}

\begin{abstract}
The main goal of this investigation was to determine if there is a more effective approach among focus on forms, focus on meaning, or focus on form for teaching the direct object pronouns to beginning students of Spanish. It will be beneficial to discover which of these three widely-used approaches can best help students to acquire correct pronoun use, and may aid instructors of Spanish in the teaching of these pronouns. In order to compare these approaches, three sections of a beginning Spanish course received instruction in one of the three approaches. The participants of this study were 51 beginning level students who had had 3 years of Spanish instruction at the high school level and were native speakers of English. The study follows a pretest/posttest design. Results find positive results for form-focused instruction over purely meaning-focused instruction for teaching the Spanish direct object pronouns with regards to sentence completion tasks. A main implication of this study is that focus on meaning instruction is not sufficient to help beginning learners improve their production of Spanish direct object pronouns. While results show a more positive impact for focus on form instruction over the more traditional focus on forms approach, additional research comparing these two methods is suggested. It is also important to note that beginning level learners show overall low levels of accuracy with direct object pronouns in Spanish.
\end{abstract}

Keywords: Second Language; Focus on Meaning; Focus on Form; Focus on Forms; Direct Object Pronouns

\section{Introduction}

Recent research on the effects of instruction in second language acquisition (SLA) has included numerous studies on attention to form in the language classroom. These studies have demonstrated a need for second language (L2) learners to have attention to form in order to develop more target-like L2 grammars. How to accomplish successful attention to form within a classroom setting while providing the necessary amount of attention and the right type of attention can be difficult to determine. Many formal language programs seek to provide the most natural environment for learning a L2 and accomplish this through meaning-focused instruction. A popular form of meaning-focused instruction is the communicative approach, which believes in developing communicative competence through meaning-based language use. The communicative approach stems from the belief that language learners will acquire their L2 grammar by using language as a tool to complete communicative tasks as they would in a real-world setting. The debate that arises with this type of instruction, centers on learners' ability to focus on form during meaningful interaction. In order to accomplish this, learners need to simultaneously focus on the meaning of the language and its linguistic form in both the input they are receiving and in the output that they are producing. Is it possible that learners can gain linguistic information and incorporate it into their L2 grammar during this

\footnotetext{
*Comparing Focus on Meaning, Focus on Form and Focus on Forms.
}

interaction? Or do learners need more explicit direction to assist them in attending to linguistic form while in the context of a meaning-based task.

This study seeks to discover if L2 learners of Spanish will benefit more from form-focused instruction or meaning-based instruction when they encounter a new linguistic form. Additionally when considering the type of form-focused instruction, this study hopes to determine if learners benefit more from a focus on form within meaning-based tasks, or from a more traditional focus on forms requiring more explicit practice of the linguistic form. In order to carry out this comparison of approaches, the specific linguistic forms used in this study are the Spanish direct object clitic pronouns. The Spanish direct object clitic pronouns have a strong connection between form and meaning, making them a useful linguistic element to compare in this study. Additionally, the direct object clitic pronouns are known to be a problematic linguistic element for L2 learners to acquire. Therefore, if it can be determined that a more effective teaching approach exists for teaching the direct object clitic pronouns, it will be advantageous to both instructors and learners.

\section{Literature Review}

\section{Three Approaches to Language Instruction}

Focus on Meaning (FoM)

As discussed by Long and Robinson (1998), in a meaning- 
based or communicative approach, learners acquire the L2 from experience with comprehensible input and from using the L2 as means of communication rather than viewing the L2 as an object of study. Omaggio Hadley (2001) furthers this explanation with three main principles for the communicative approach: First, meaning is central and the contextualization of the grammatical elements is essential when presenting foreign language grammar to learners. Second, language learning happens with communication and negotiation of meaning, therefore learners must communicate with the language from the beginning of instruction. Third, the goal of this approach is communicative competence focusing primarily on fluency and the ability to use the language to express learners' own ideas and thoughts. Based on these explanations, a main emphasis of a communicative approach is on providing a sufficient quantity of comprehensible input to allow learners to see what is possible in the L2. In addition to this comprehensible input, a communicative approach offers the opportunity to practice speaking and writing in the $\mathrm{L} 2$ as means of communication, not simply as pronunciation practice or grammar skill practice (Howatt, 1987).

\section{Focus on Form (FoF)}

A focus on form teaching approach, as outlined by Long and Robinson (1998) "consists of an occasional shift of attention to linguistic code features - by the teacher and/or one or more students - triggered by perceived problems with comprehension or production" (p. 23). In a focus on form approach, the instructor can actively provide negative feedback during interaction (as a participant or observer of the interaction) to help redirect student attention to linguistic form. Long and Robinson suggest use of focus on form during activities and through implicit negative feedback. During an activity, learners work together to solve a problem, where the focus is on meaning and resolving the issue at hand. Although the learners are not asked to use a specific form, the task encourages the use of a form and increases the probability of the form being noticed and integrated into speech and writing. As learners work, the instructor circulates among them and interrupts in order to focus attention to linguistic problems for the specific form being targeted. In other words, if direct object pronouns are is the form being targeted, the instructor will only address errors that occur with direct object pronouns.

Another type of focus on form has been called "proactive" by Doughty and Williams (1998) and is described as being more feasible in a language classroom than the more reactive approach prescribed by Long (1991). With proactive lessons, not only is there a higher opportunity for learners to use a particular form, but in addition instructors can be more sensitive to possible learner errors of that form and can maintain their own focus to correct only those errors which occur in the form at hand. (Doughty \& Williams, 1998) As stated by both Lightbown (1998) and Doughty and Williams, these activities do not need to be unnatural or contrived to use a specific form. It is still possible to create real-world situational communicative activeties and maintain a focus on form. Lightbown upholds that "teachers are not 'traitors' to the cause of communicative language teaching if they plan activities in which they know that learners will almost inevitably need to use specific linguistic features" (p. 195).

\section{Focus on Forms (FoFS)}

Many language researchers consider attention to grammatical form to be an important part of second language acquisition. Schmidt (1990) states that grammar reformation principally transpires when learners concentrate on and notice elements in the input. In order to achieve this noticing of information in the $\mathrm{L} 2$, learners must have some focus on grammatical form, though, how much attention is paid to form can be a critical decision in developing an instructional approach. One such approach that puts major emphasis on linguistic form is the more traditional, focus on forms approach. Long (1991) emphasizes the plural forms in this approach because rather than focusing on meaning or focusing on form within meaning, a course that uses focus on forms instruction focuses on the grammatical forms themselves. Stemming from the more traditional methods of teaching foreign language, a focus on forms approach employs the use of formal grammar explanation and grammar production activities. Two main elements of this grammar production include the frequent drilling of a grammatical sequence and the intensity with which the drilling or practicing of the grammatical sequence is done. Sheen (2005), an advocate for focus on forms approaches, suggests that this approach does not need to be entirely a forms-in-isolation type of grammar teaching, but instead can be a skills-learning approach. Sheen defines focus on forms as having three phases: first, instruction presents knowledge of the L2 grammar in a variety of ways including explanation in the L1 and distinguishing differences between the L1 and the L2; second, learners complete written and oral exercises using the forms in both non-communicative and communicative activities, and third, learners are provided with opportunities for communicative use of the grammar to promote automatic and accurate use. His definition, while encompassing more recent ideas of meaning-focused communicative activities in some parts of the instruction, is still, on the whole, a traditional approach that sees the L2 as an object of study and places the majority of focus on the grammar itself.

\section{Comparing Approaches}

In order to better understand which of these approaches may be most beneficial to L2 learners, researchers have carried out investigations comparing the learning outcomes for a variety of grammatical structures and languages. Most research projects have compared FoM to FoF as a result of the perceived need for additional attention to form in the classroom. Earlier studies, such as Harley and Swain (1984) and Swain (1985), found that in a purely communicative learning environment, learners developed strong communication skills and fluid speech but lacked in grammatical understanding and accuracy. It was from studies such as those that the need for attention to form in the language classroom was highlighted by researchers and instructors alike. This need has been supported by research in that results of studies comparing FoM to FoF have been positive for FoF over FoM (Lightbown \& Spada, 1990; Doughty \& Varela, 1998; Han, 2002; Lyster, 2004; Spada, Lightbown, \& White, 2005; Grim, 2008; Pishghadam, Khodadady, \& Rad, 2011). Overall, L2 learners receiving FoF instruction significantly improved in the structure being acquired and significantly improved more than the FoM learners. These results have been shown for both proactive FoF and incidental FoF (although in most studies the FoF has been proactive).

In further looking at the extent of form-focused instruction, a few researchers have compared FoF with FoFS. The first of 
these studies conducted by Sheen (2005) found that learners receiving FoFS significantly outperformed the FoF learners. However, in his article, Sheen does not clearly explain the FoF instructional treatment that the learners received, making it difficult to determine if the FoF group from his study can be compared to FoF groups in other studies. Further, the FoFS group used practice activities that were very similar to the testing procedures making it unclear if their significant improvement was a result of rehearsal of the activity or if it is a true indication of improved understanding and accuracy of the target forms. Other more recent research, Saeidi, Zaferanieh \& Shatery (2012) and Rahimpour, Salimi \& Farrokhi (2012) ${ }^{1}$ have found positive results for FoF over FoFS in that the learners from their studies showed both significant improvements in the target structures and improved significantly more than the FoFS groups. Of particular interest to the current study, Saeidi et al. also compared FoM to FoF and FoFS and finds that while the FoF group improved significantly more than both FoM and FoFS, the FoM group also significantly outperformed the FoFS learners. Such a finding indicates that meaning-based learning can have a greater impact on the acquisition of a given structure over a more abstract, traditional approach.

\section{Spanish Direct Object Clitic Pronouns}

As discussed in several studies (for example Spada, Lightbown \& White, 2005), a grammatical element that has a strong link between form and meaning can be understood and acquired by learners through a focus on form approach. An example of a grammatical element in Spanish with this strong relationship is the object pronouns or clitics. The object clitics in Spanish are proclitic for verb phrases with a single verb, creating a structure that appears to be (S)OV to learners of Spanish ${ }^{2}$. In verb phrases with two (or more) verbs (such as a conjugated verb and an infinitive) the clitic may be proclitic or enclitic. In the enclitic case, although there is now the appearance of (S)VO ordering, it still does not follow standard (S)VO in that the clitic no longer stands alone as a single word. In addition to the morphosyntactic properties of clitics, there are also strict agreement rules that must be followed. The Spanish clitics must inflect for gender, number, and in some instances, case, with respect to the antecedent. For these reasons, clitics have a high level of difficulty for second language learners not only at the beginning levels but also at advanced levels. Due to the strong link between form and meaning and the difficulty shown by beginning learners, direct object pronouns were chosen as the grammatical form to be used in this study. The researcher also believed that if this study can infer that there is a more effective approach for teaching direct object pronouns that would be beneficial in helping learners to overcome these problems.

A large amount of acquisition research of the clitics has dealt with learners' difficulty in understanding the overall meaning of sentences that contain clitics due to the word order. To explain this difficulty, the idea of First Noun Strategy has been discussed by many acquisition researchers such as VanPatten (1984, 1996), VanPatten and Cadierno (1993), Lee (2003), and Camps (2003). This strategy states that learners make the assumption that the first noun in a given sentence is the subject of

${ }^{1}$ Rahimpour et al. (2012) uses the terms intensive Focus on Form for FoF and extensive Focus on Form for FoFS.

${ }^{2} \mathrm{~A}$ more in depth syntactic and morphological evaluation would show that the deep structure is still SVO (Haspelmath, 2002). that sentence, thus creating a SVO word order. Therefore when learners' encounter a sentence that contains a preverbal clitic and a post verbal or dropped subject they often misinterpret the clitic as the subject. An example of this misinterpretation comes from VanPatten (1984):

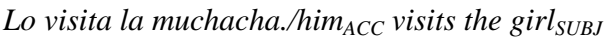 \\ The girl visits him.- correct interpretation \\ He visits the girl.--incorrect interpretation}

Empirical research (VanPatten, 1984; Lee, 1987; Houston, 1997) has confirmed this strategy in that L2 learners of Spanish (particularly beginners) frequently assume the clitic pronoun to be the subject rather than the object leading to a general misunderstanding of the function of these pronouns.

In order to discourage the First Noun Strategy, VanPatten (1983) developed a form-focused teaching approach called Processing Instruction (PI), which attempts to change the way in which learners identify and process grammatical elements in the input they receive. In practice, PI generally follows a three step procedure of correct processing strategies, incorrect processing strategies, and activities using structure input: First, learners receive explicit explanation of the structure. Second, learners learn about processing strategies to help them correctly interpret input and processing strategies that cause misinterprettation of input. Third, learners complete processing activities with structured input that follows guidelines four, five, and six. In PI learners do not complete production activities of the grammar element being learned.

Research into the impact of PI on pronoun acquisition (VanPatten \& Cadierno, 1993; VanPatten \& Sanz, 1995; VanPatten \& Oikkenon, 1996; VanPatten \& Fernández, 2004) found that learners receiving PI significantly improved in both interpretation of sentences with direct object pronouns and in the production of those pronouns. These learners showed significantly better understanding of sentences with pronouns over learners that did not receive PI. In regards to production, the PI learners were able to correctly produce pronouns with an equivalent level of accuracy as the other learners. While the current research study does not use PI, it is important to recognize that form-focused instruction with meaning-based activities is beneficial in acquiring Spanish direct object pronouns.

\section{Methodology}

As stated previously, the main goals of this study are to compare students' accuracy in using direct object pronouns after receiving one of three types of instruction in this area: focus on form (FoF), focus on meaning (FoM), or focus on forms (FoFS). The specific research questions that guided the study are as follows:

1) For each approach, is there a significant level of improvement in direct object pronoun production following instructtion?

2) With regard to student improvement in direct object pronoun production, are there any significant differences seen between the three teaching methods employed?

\section{Participants}

Three sections of a beginning-level Spanish course at a large North American university participated in the study. The course was a three credit hour undergraduate course designed for stu- 
dents who had an introduction to Spanish in high school (1 year) but were still considered to be at the beginning level. A FoM approach was normally used in this course by all instructors. The principal investigator was the instructor for two of these sections and a second instructor taught the third section. The students that participated in this study were all native speakers of English and were not considered to be bilingual. These students did not have regular contact with Spanish outside of the classroom $^{3}$. In total 51 students attended all sessions and constitute the final number of participants.

These three sections of the course were assigned at random to three instructional approaches: a FoF group $(\mathrm{n}=19)$, a FoM group $(n=18)$, and a FoFS group $(n=14)$. Due to this random assignment, the principal investigator was the instructor for the FoF and FoM groups. The second instructor taught the FoFS group. The FoM group was designed to be a comparison group for the other two since they continued with their normal type of instruction. All three groups followed the same study plan: a pretest, an instructional day, and a posttest.

\section{Procedures}

The pretest was administered prior to any instruction of the direct object pronouns. The pretest was used to determine to what extent the participants were already skilled in the use of direct object pronouns ${ }^{4}$. It was decided that any student who scored higher than $60 \%$ on either task on the pretest would be eliminated from the study to ensure that the results obtained here could be correlated to the instruction technique the students received.

Following the pretest, all groups received instruction and then completed in-class activities geared toward the type of instruction. More information regarding specific teaching and practice design will be discussed below. The class syllabus allots only one day of instruction for direct object pronouns, as such, it was determined that it would be unrealistic to incorporate additional treatment merely for the purposes of this study ${ }^{5}$. Following the instruction day, the posttest was administered during the next class meeting time.

\section{Test Design}

Two versions of a written test (Quiz A and Quiz B) ${ }^{6}$ were created to be used as the pre- and posttests. Tests were administered so that students did not take the same version twice, to eliminate a possibility of improvement due to test familiarity. Each test consisted of two activities: a lower communicative value activity and a higher communicative value activity. The lower communicative value activity consisted of five fill-in-theblank sentences with the instructions to fill in the blanks appropriately to complete the sentence; students were not specifically instructed to use direct object pronouns. This activity was directly based on the example tests used in Camps (1997). Four of the five sentences required the student to conjugate a verb in parenthesis and add a direct object pronoun as seen in Example

\footnotetext{
${ }^{3}$ Any students not present on the day of instruction or who did not complete all testing materials were eliminated from the participant pool.

${ }^{4}$ Since students had taken 1 year of high school Spanish there was a possibility that they had prior exposure to direct object pronouns.

${ }^{5}$ There were other sections of the course that did not participate in the study and providing additional instructional time was deemed to be unfair to other students.

${ }^{6}$ They were called quizzes instead of tests so as not to confuse students with respect to course grading.
}

1.

Example 1 with correct response provided:

Pilar necesita su libro y lo busca (buscar) por la casa.

Pilar needs her book and she looks for it (to look for) throughout the house.

One of the five sentences was used as a distracter and did not require a direct object. This activity was a mechanical activity requiring students to conjugate the verb correctly and provide the correct pronoun based on the antecedent in the beginning of the sentence, and was therefore considered to have a lower communicative value: there is only one possible answer and there is no opportunity for self-expression on behalf of the student.

The higher communicative value activity consisted of four open-ended questions with instructions to answer the questions by writing a complete sentence. All of the questions contained a direct object, giving the students the option to use the direct object pronouns; once again students were not specifically instructed to use direct object pronouns. An example of this type of question is seen below.

Example 2 with possible correct response provided: ¿Dónde haces la tarea normalmente? La hago en la biblioteca.

Where do you normally do your homework? I do it in the library

This activity is considered more communicative than the fill-in-the-blank portion of the test because it allows the student more opportunity to express his/her own ideas. It is not, however, a truly communicative activity, such as free-writing composition would be, because the students are limited to only a few possible responses and must still use the given antecedent.

\section{Instructional Day}

All instructional groups followed a similar plan on the day of instruction. Class began with a general oral activity using vocabulary from the current chapter as a warm-up to the class. After completing this activity, the instructor led the group through a PowerPoint presentation about direct object pronouns. Next, the groups completed both oral and written activities using direct object pronouns. Finally, each group received a homework assignment to continue practice of direct object pronouns. Additionally, in the FoF and FoM groups the need to complete homework helped as a motivator to complete the in-class assignment. Prior to the instructional day, all students were expected to read over the grammar explanation of direct object pronouns in the textbook.

\section{FoFS Group Instructional Design}

Pre-activity. The FoFS group began their class with a choral repetition exercise from their activity book. This exercise focused on the vowel sounds in Spanish and used vocabulary words from the chapter; it did not involve any direct object pronouns. The instructor read each word aloud and the students repeated the word after the instructor.

PowerPoint presentation. The intention of this group's presentation was to offer a detailed and thorough grammatical explanation of direct object pronouns. By explicitly explaining all details of the grammar and reviewing other aspects of Spanish grammar, such as grammatical gender, the instructor main- 
tained a FoFS approach to grammar teaching. In addition to keeping with a FoFS approach, the pronouns were discussed in an abstract manner, lacking context or meaning for the most part. The presentation consisted of three slides, beginning with the paradigm of direct object pronouns showing both the Spanish and English pronouns. The instructor overtly reviewed each pronoun and its English counterpart. For the direct object pronouns in the third person, the instructor reminded students of the presence of grammatical gender on Spanish nouns and pointed out the importance of gender and number and the need for agreement between the noun antecedent and the pronoun. The second slide explained that pronouns may substitute for nouns and gave two examples of pronouns in a question with a direct object and two possible answers to the question: one repeating the noun and the other using the pronoun. The instructor explicitly explained the substitution of the noun with a direct object pronoun. The instructor also reiterated the importance of gender and number agreement between the antecedent and the pronoun. The third slide explained pronoun placement in Spanish for verb phrases containing a single conjugated verb and those that contain two verbs (such as the present progressive). Again, the instructor explicitly explained the placement of these pronouns. In addition to the placement, the instructor also reviewed the standard accent rules for Spanish and the need for a written accent mark in the gerund in the case of a pronoun attaching to that gerund.

In-class activities. The in-class activities used for this group were drill-style mechanical activities requiring the students to produce the correct direct object pronoun. During all activities, the instructor provided explicit corrective feedback for all grammar errors observed. In the first two in-class activities there was only one possible correct answer for each question. The first activity was an oral instructor-to-student exercise from the textbook. It consisted of matching direct object pronouns with a subject pronoun or proper name. For example, 1. los (them) matched to c. Pedro y Carolina (Pedro and Carolina). The next activity was also from the textbook and consisted of combining two sentences, both using the same direct object, to one sentence with the direct object and its corresponding pronoun. Students completed this activity in small groups. While students were working, the instructor circulated around the room and responded to student questions. When the students had finished, the instructor asked for the answers and then wrote student responses on the board explicitly correcting any errors as they arose. In the third in-class activity and the homework assignment, the students had more opportunity to express their own ideas beyond one correct answer; however, they were still restricted to only one correct direct object pronoun. This activity consisted of four questions with the instructions to answer the questions using direct object pronouns. As with the previous activity, the instructor circulated around the room and responded to student questions while they were working and corrected all errors as they were heard. Again as a follow-up to the activity, the instructor asked for possible answers and wrote student responses on the board, correcting their errors.

Out-of-class activity. For homework, the students were assigned a written assignment similar to the last in-class activity with questions containing a direct object. In these questions the direct object was underlined and students were instructed to answer using direct object pronouns.

\section{FoM Group Instructional Design}

Pre-activity. The activity consisted of three open-ended personal questions about the food vocabulary from the current chapter; they were not related to direct object pronouns. Students took turns asking and answering the questions with a partner. As a follow-up activity the instructor posed the questions to the class and took volunteer responses to demonstrate possible answers.

PowerPoint presentation. Students were instructed to open their textbooks to the direct object pronoun explanation during their PowerPoint presentation. In doing so, the students had access to the pronoun paradigm and the book's English-written explanation. The first slide consisted of three examples of questions containing a direct object and two possible answers: one repeated the direct object and one used the direct object pronoun. With these examples, students were able to see the grammar point in a conversational context and had the opportunity to make the connection between the direct object and the pronoun without having an explicit grammar explanation. The second slide used a new set of examples of more complex questions and responses using the direct object pronouns. This second set of examples provided more variety of verbal structures and pronoun placement. As with the previous examples, an explicit explanation of pronoun placement was not used; instead the conversational context allowed the students to see this placement as it would occur in natural speech. The third slide consisted of a set of compound sentences describing a party. All of these sentences used a direct object in the beginning of the sentence and its corresponding direct object pronoun in the second part of the sentence. As before, the students did not receive an explicit grammar explanation of these sentences, but were able to see how pronouns could be used in another type of situation. Throughout the presentation, the focus was on understanding the meaning of the sentences and to maintain student involvement, the instructor asked questions regarding that meaning. Direct grammar points were only addressed if students posed a direct grammar question to the instructor. For example after seeing and hearing the sentence Yo cocino un pastel y lo traigo a la fiesta a student asked "Does lo mean the cake?” and the instructor responded that indeed lo referred to el pastel or "the cake" in that sentence.

In-class activities. The activities chosen for the FoM group were all activities that allowed students to focus on meaning while using the direct object pronouns. During the activities, the instructor did not offer corrective feedback unless in the case of a serious communication breakdown. In such a case, implicit feedback (recasts or questions) were used. The first activity consisted of two parts: one that was instructor-to-student and a second that was student-to-student. For this activity, the instructor had a collection of plastic food items, all of which was vocabulary from the current chapter. For the first part of the activity, the students had to obtain food from the instructor. The instructor would first announce the food item and then ask who wanted it using the appropriate direct object pronoun. For example, the Instructor said "Tengo un pollo. ¿Quién lo quiere?” (“I have a chicken. Who wants it?”). Students were allowed to answer as they wanted either with the name of the food item or with a direct object pronoun. As long as the correct meaning was conveyed, the student received the food item. There was some prompting by the instructor to encourage complete sentences. Additionally, the instructor made sure that each student had at least one food item by the end of the activity. For 
the second part of the activity, the students had to interact with their classmates and try to obtain different food items with the intention of creating the best possible meal for themselves. In order to help the students understand this exchange, the instructor modeled conversations with a couple of students in front of the class using direct object pronouns. After the students had the general idea, they began their own food transactions, during which, the instructor circulated throughout the class, responding to questions. As a follow-up to this activity, the instructor asked students what they had collected and why they thought it was a good meal. After this, the instructor requested the items back using direct object pronouns. The next activity was a student-to-student writing and speaking activity. The activity was to plan a dinner party for the class with a partner. First, on their own, the students made a brief list of items they would need for the party. Then the students pretended to call their partner and discussed plans for the party. In this way, the students needed to talk about their ideas but could not just show their list to their partner. As part of the directions for the activity, the instructor modeled some possibilities for the party plans utilizing direct object pronouns to once again demonstrate how direct object pronouns can be used in everyday speech. In addition, during the planning students were told to take notes for their homework. As with the previous activity, while students were working together, the instructor circulated and answered questions as needed.

Out-of-class activity. For their written homework assignment, the students had to write up their party plans in paragraph form. While giving the instructions for the assignment, the instructor also gave a few model sentences to guide the students. The sentences contained both direct objects and the corresponding direct object pronouns. However, in the directions the students were not explicitly told to use direct object pronouns. The motivation for assigning homework for the FoM group was to motivate the students to actively participate in the final inclass activity. The researcher believed that if the students knew that they would need the information from that activity for a homework assignment, they would try their very best during that activity.

\section{FoF Group Instructional Design}

The focus on form instruction developed for this study was developed primarily from the more proactive or planned focus on form approach as presented in Doughty and Williams (1998), Ellis, Basturkmen, \& Loewen (2001), Grim (2008) or Qin (2008). In this study's version of focus on form, meaning-based activities were chosen based on their opportunities to use the direct object pronouns. During these meaning-based activities corrective feedback was only given for errors made with the direct object pronouns. Additionally, based on the ideas from Processing Instruction (VanPatten, 1993) of preparing students for possible difficulties with a grammar element, the researcher chose to take the idea of proactive focus on form further and offer the students a brief grammar explanation highlighting difficult features of the direct object pronouns. It is important to note that the version of focus on form used in this study is different from Long's (1991) original definition.

Pre-activity. The FoF group began with the same oral activity as the FoM group, working with a partner to answer questions that encouraged use of the vocabulary from the current chapter. Again, the instructor followed-up this activity by asking individual students for their possible responses.
PowerPoint presentation. Students were instructed to open their textbooks to the given explanation of direct object pronouns. Altogether, the goal of these slides for the FoF group was to offer a brief introduction to the direct object pronouns in a meaningful context. The presentation was also intended to highlight the most important and difficult aspects from the grammar reading in the textbook. Building on the idea of a preemptive focus on form (Ellis et al., 2001), the presentation was a way to quickly and efficiently discuss key elements of direct object pronouns in anticipation of student questions and problems. Because the presentation was offered from the instructor, it is impossible to know if these topics were actually lacking in the students' metalinguistic knowledge of direct object pronouns. However, based on a reading of the textbook grammar description, it can probably be safely assumed that the students did not yet fully understand the use of direct object pronouns and further clarification could only be beneficial to them. As opposed to a very technical and abstract focus on forms grammar explanation of these pronouns, this presentation was meant to refresh the students' memories and prepare them to use direct object pronouns in the communicative in-class activities.

The first slide for this presentation was the same as the first slide for the focus on meaning group. It shows three sets of examples consisting of a question with a direct object and one response that repeats the direct object and a second that uses the direct object pronoun. In addition, while showing this slide, the instructor actively pointed out the connection between the antecedent and the pronoun. The second slide in this presentation shows the direct object pronoun paradigm with the English translation. The instructor briefly reviewed the pronouns with the students and pointed out the importance of agreement with gender and number for the third person object pronouns. The third slide contained both examples of direct object pronouns in more complex sentences with a variety of verbal structures and statements in English about pronoun placement. When reviewing this slide, the instructor focused on pronoun placement only and did not give an in-depth grammar explanation beyond the two English statements from the slide.

In-class activities. Following this presentation, the FoF group completed the same two activities using the direct object pronouns as the FoM group, with a few changes to adjust them to a focus on form approach. In this way, the students were focused on completing a meaningful task and not focused on only using a grammar element. The main difference between the activities for the FoF group and the FoM group was the corrective feedback given by the instructor. During both activities, implicit feedback in the form of recasts and questions was offered when errors with direct object pronouns were observed. In this way, the instructor was assisting the students to focus on form while still maintaining a focus on meaning. Other grammatical errors were ignored by the instructor during the activities.

Another difference between the two groups occurred in the first activity. In the instructions for the first in-class activity, the focus on form group was explicitly told to use direct object pronouns. The reason for this was to push the students to try the new forms and begin to incorporate them into their own language use. If they were allowed to use either the noun or the corresponding pronoun, the researcher believed that there was a strong possibility that the students would continue to use the nouns because they felt comfortable with that structure and 
knew it to be correct. By completing an activity that first forced them to use the pronouns, it was hoped that they would become comfortable enough to use them again, when the opportunity arose, without being told to do so. In the second in-class activiity and the homework assignment, the students were not explicitly told to use direct object pronouns. The reason for this was to allow the students to recognize the opportunity for direct object pronouns. Again, to help the students do this, the instructor offered corrective feedback to bring the students' attention back to the direct object pronouns within the context of the activity. Within this activity many of these prompts were preemptive to suggest to students to use direct object pronouns. For example if a student was using the same direct object over and over again instead of the direct object pronoun, the instructor asked if it was possible to avoid that repetitiveness in some way.

Out-of-class activity. For their written homework assignment, just as the focus on meaning group, the students had to write up their party plans in paragraph form. In the directions the students were not explicitly told to use direct object pronouns. Again, the purpose of the homework was to inspire the students to participate fully in the final in-class activity.

\section{Data Analysis}

\section{Test Scoring}

All tests were scored in the same manner. A completely correct response that used the correct direct object pronoun and correct placement of that pronoun received a score of two points. A response that used a pronoun but still had at least one pronoun error received a score of one point. These responses might include the use of the incorrect direct object pronoun, incorrect pronoun placement, or use of some other type of pronoun (indirect or reflexive). A response that did not use any pronoun received a score of zero points. The total score possible on each test activity was eight points.

\section{Statistical Analysis}

The data for the two tests (sentence completion and questions) were analyzed separately due to the difference in test style. The first analysis that was run for each data set was a univariate ANOVA of the pretest scores in order to determine that there was no significant difference between the groups prior to instruction. The second analysis for each data set was a simple means analysis using the raw scores to determine the mean scores for each test and each group. Next a $3 \times 3$ ANOVA was run to determine the effect of time, group, and a possible interaction between time and group. If a significant value was found for group, post-hoc tests (Tukey and Scheffe) were run to better understand the significance differences between the groups. Additionally a t-test was run for each group to analyze the differences between the tests for that group.

\section{Results and Discussion}

\section{Sentence Completion Data}

An ANOVA was first completed for the pretest for all three instructional groups and did not yield a significant effect for group, $\mathrm{F}=1.532, \mathrm{df}=2, p=.227$, confirming that at the time of the pretest the three instructional groups were at the same level of knowledge for the direct object pronouns. The mean scores for the sentence completion data show that participants im- proved overall from the pretest to posttest and can be seen in Table 1. The total possible score for the sentence completion was 8. Individually, the FoFS instruction group rose from a pretest mean of .36 (lowest score 0 , highest score 2) to a posttest mean of 1.50 (lowest score 0 , highest score 8). The FoF instruction group rose from a pretest mean of .16 (lowest score 0 , highest score 3 ) to a posttest mean of 2.63 (lowest score 0 , highest score 8). The FoM instruction group made no change from pretest to posttest (for both the mean was .00, all scores $0)$.

A repeated measures ANOVA was completed for all data and yielded statistically significant effects for time, $(p=.000)$, group, $(p=.049)$, and time and group, $(p=.014)$. These results can be seen in Table 2. A univariate ANOVA was completed for the posttest to determine the differences between the instructional groups. The ANOVA yielded a significant effect for group, $\mathrm{F}=4.819$, $\mathrm{df}=2, p=.012$. Additionally, post-hoc Tukey HSD and Scheffe tests yielded a statistically significant difference between the FoF group and the FoM group in favor of the FoF group, $p=.009$ and $p=.013$, respectively.

To further see the details of the progress made by the individual groups, each group was analyzed first with a repeated measures ANOVA. After that, in order to determine the progression between tests, post hoc comparisons were done using t-tests. Neither the FoFS group nor the FoM groups showed statistically significant improvement overtime. However, it should be noted that the FoFS group did show some improvement in their test scores at the time of the posttest, albeit nonsignificant, whereas the FoM group produced no improvement at all. For the FoF group, the ANOVA yielded a significant effect for time, $\mathrm{F}=6.915, \mathrm{df}=2, p=.003$. The t-test for this group showed a significant improvement between the pretest and posttest, $p=.006$.

These results indicate that the FoF group benefitted from their instruction more than the learners in the FoM and FoFS groups. Looking at the significant difference between the FoF and FoM groups, the findings support the theory that L2 learners will benefit from more attention to form when completing

Table 1.

Mean scores on the sentence completion task.

\begin{tabular}{cccccc}
\hline & \multicolumn{2}{c}{ Pretest } & \multicolumn{2}{c}{ Posttest } \\
\hline Group & $\mathbf{n}$ & Mean & SD & Mean & SD \\
Focus on Forms & 14 & .36 & .745 & 1.50 & 2.902 \\
Focus on Meaning & 18 & .00 & .000 & .00 & .00 \\
Focus on Form & 19 & .16 & .688 & 2.63 & 3.419 \\
\hline
\end{tabular}

Table 2.

Repeated measures ANOVA for the sentence completion task.

\begin{tabular}{cccc}
\hline & $\boldsymbol{d} \boldsymbol{f}$ & $\boldsymbol{F}$ & $\boldsymbol{p}$ \\
\hline Source of variation & & & \\
Time & 2 & 10.681 & .000 \\
Group & 2 & 3.205 & .049 \\
Time $\times$ Group & 4 & 3.303 & .014 \\
\hline
\end{tabular}

Note: Significance was set at .05. 
meaningful activities which encourage the use of that form. As was seen in prior research (Lightbown \& Spada, 1990; Doughty \& Varela, 1998; Han, 2002; Lyster, 2004; Spada, Lightbown, \& White, 2005; Grim, 2008; Pishghadam, Khodadady, \& Rad, 2011) the FoF group, which received the greater explanation and attention to form, performed significantly better than the communicative (FoM) group immediately following instruction. As in these prior studies, the FoM group did not show any significant improvement after instruction. From these results, it appears that beginning-level Spanish learners have a need for focus on form and a greater attention to grammar when learning the direct object pronouns. In particular, helping students to identify the need for the pronouns and strengthening the link between those small words and the overall meaning of statements can help them with pronoun production. Although errors were made with some pronouns used, the FoF learners better recognized the need to use pronouns in these sentences, whereas the FoM group rarely saw such a need.

When considering the differences seen between the FoF and the FoFS group, it can be seen that the attention to form plus meaning appears to lead to greater improvement in pronoun use; however, a significant difference between the groups was not found. The FoFS group, like the FoF learners, was able to have some improvement between the tests. While the improvement seen for FoFS was not significant, the increase in correct pronoun use led to a non-significant difference between the FoF and FoFS groups for the posttest. This finding indicates that some type of form-focused instruction is preferable to purely meaning-focused instruction for the direct object pronouns, but it is not entirely clear if a focus on form approach can be more effective than a more traditional focus on forms approach. This result somewhat supports the findings of Saeidi et al. (2012) and Rahimpour et al. (2012) in that it demonstrates a small positive finding for FoF over FoFS. Nonetheless, those studies were able to show that the FoF groups significantly outperformed the FoFS groups.

Returning to the hypothesis of Spada, Lightbown and White (2005), focus on form instruction is most effective with grammatical structures that have a high link between form and meaning. Knowing that the Spanish direct object pronouns have this strong connection between form and meaning, the results from this study correlate with this hypothesis. In focusing on the meaning of the pronouns throughout the instructional activities, it appears that the learners in the FoF group were better able to establish a connection between the form and the meaning, and consequently recognized the opportunity to use pronouns on their posttest to have meaningful and grammatically correct sentences more than the other two groups. Following this conclusion, a t-test was run on the amount of pronouns used on the posttest to determine if a group produced significantly more pronouns than the others. It was found that the FoF group significantly produced more pronouns than either the FoFS or FoM group, $p=.021$. Although some of these pronoun uses were incorrect (discussed below) the FoF learners appeared to have recognized the need for direct object pronouns more than the other two instructional groups.

It is important to point out that although improvement was seen over time, the learners' use of direct object pronouns was still considerably nontarget-like. A considerable amount of learners in all groups showed little or no improvement in their abilities to produce direct object pronouns. This is similar to S's (2000) findings that learner results were well below those of native speakers. It is therefore comprehensible that whichever approach is chosen, there may be a need for more practice and instruction of the direct object pronouns before learners are able to demonstrate target-like production.

\section{Question Data}

As with the sentence completion data, an ANOVA was first completed for the pretest for the instructional groups and did not yield a significant effect for group, $\mathrm{F}=.837, \mathrm{df}=2, p$ $=.439$, confirming that at the time of the pretest the three groups were at the same level of knowledge for the direct object pronouns. The mean scores for the question data show that participants improved slightly overall and can be seen in Table 3. As with the sentence completion data, the total score possible was 8. Individually, the FoFS instruction group rose from a pretest mean of .00 (all scores 0 ) to a posttest mean of 1.50 (lowest score 0, highest score 8). The FoF instruction group rose from a pretest mean of .05 (lowest score 0 , highest score 1 ) to a posttest mean of .47 (lowest score 0 , highest score 7 ). The FoM instruction group made no change from pretest to posttest (for both the mean was .00, all scores 0).

A repeated measures ANOVA was completed for all data but no statistically significant effects were seen. These results can be seen in Table 4. To further explore if there was any effect for group in the posttest, a univariate ANOVA was completed but did not yield a significant effect for group, $\mathrm{F}=2.856$, $\mathrm{df}=2$, $p=.067$.

Again, to examine the details of the progress made by the individual groups, each group was analyzed first with a repeated measures ANOVA. After that, in order to determine the progression between tests, post hocs comparisons were done using t-tests. No group showed significant progress over time, indicating that although a slight improvement was seen in the FoFS and FoF groups, this change was only minor.

Unlike with the sentence completing data, the results do not show an impact of instructional approach since no group made significant improvement. However, when looking at the mean

Table 3.

Mean scores on the question task.

\begin{tabular}{cccccc}
\hline & \multicolumn{2}{c}{ Pretest } & \multicolumn{2}{c}{ Posttest } \\
\hline Group & $\mathbf{n}$ & Mean & SD & Mean & SD \\
Focus on Forms & 14 & .00 & .000 & 1.50 & 2.849 \\
Focus on meaning & 18 & .00 & .000 & .00 & .00 \\
Focus on Form & 19 & .05 & .229 & .47 & 1.611 \\
\hline
\end{tabular}

Table 4.

Repeated measures ANOVA for the question task.

\begin{tabular}{cccc}
\hline & $\boldsymbol{d} \boldsymbol{f}$ & $\boldsymbol{F}$ & $\boldsymbol{p}$ \\
\hline Source of variation & & & \\
Time & 2 & 2.784 & .072 \\
Group & 2 & 2.661 & .080 \\
Time $\times$ Group & 4 & 2.000 & .101 \\
\hline
\end{tabular}

Note: Significance was set at .05. 
scores, it is important to note that the FoM group once again showed no improvement, while both the form-focused groups did show small improvement. This small improvement does indicate some support for the need for greater attention to form resulting in greater production and accuracy with direct object pronouns. Nonetheless, the lack of significant results indicates a need for further research into this type of pronoun production. As with the sentence data, a t-test was run on the amount of pronouns produced in the posttest, but no significant differences were found between groups. Upon further analysis of the answers, it was found that learners were most likely to produce grammatically correct sentences which repeated the antecedent rather than using a direct object pronoun. It is possible that learners recognized the opportunity to use direct object pronouns, but chose to repeat the antecedent instead because it was the better-known form of response. In some way, those may have been the "easier" answers because they did not have to worry about choice of pronoun or correct position within the sentence. However, due to the overall low use of pronouns in both test activities, it is likely that learners did not recognize the opportunity to use pronouns.

\section{Error Analysis}

In the two tests combined, there was a total 816 answers. Of this total, 89 answers used pronouns. However of these 89 uses, there were 22 instances where participants provided a pronoun but it was either used in an erroneous way and/or was an incurrect pronoun. All errors were coded by type with six types of errors found:

- position: errors with the correct direct object pronoun but the wrong position, ex. Yo necesito mi libro $y *$ busco $l o^{7}$

- indirect: errors where the student used an indirect object pronoun in place of a direct object pronoun, ex. Yo necesito mi libro $y$ *le busco

- reflexive: errors where the student used a reflexive pronoun in place of a direct object pronoun, ex. Yo necesito mi libro $y$ *se busco

- wrong direct object pronoun: errors with an incorrect direct object pronoun, ex. Yo necesito mi libro y *la busco

- wrong direct object pronoun and position: errors with both an incorrect direct object pronoun and an incorrect position, ex. Yo necesito mi libro $y$ *busco la

- indistinguishable: an error committed with the Spanish pronouns me, te, or nos which can be used as direct object, indirect object, or reflexive pronouns, ex. Yo busco mi libro $y$ *me busco

The frequency of these errors is given in Table 5. Of the error types, position was the most common error accounting for $45.45 \%$ of the errors. This indicates that participants were able to produce the correct pronoun, but rather than follow Spanish syntax rules which require the pronoun precede the conjugated verb, they placed pronouns after the verb as in English. The next most common errors were wrong direct object pronoun and position accounting for $18.18 \%$ of the errors and wrong direct object pronoun, $13.64 \%$ of errors. These errors indicate that along with position, participants had trouble identifying the correct gender and/or number for the antecedent. The analysis of these errors also showed that it is possible that participants were confusing the subject with the direct object since the pro-

${ }^{7}$ The correct response would be Yo necesito mi libro y lo busco (I need my book $_{\mathrm{M}}$ and I look for it $\mathrm{M}_{\mathrm{M}}$.
Table 5.

Frequency of all direct object pronoun errors.

\begin{tabular}{ccc}
\hline Type of Error & Frequency of Error \\
\hline Position & 45.45 & $(10)$ \\
Wrong direct object pronoun and position & 18.18 & $(4)$ \\
Wrong direct object pronoun & 13.64 & $(3)$ \\
Indirect & 9.09 & $(2)$ \\
Indistinguishable & 9.09 & $(2)$ \\
Reflexive & 4.55 & $(1)$ \\
Total Errors & & $\mathbf{2 2}$ \\
\hline
\end{tabular}

noun used often reflected the gender and/or number of the subject rather than the direct object. For example, in the sentence María compra un libro y *la lee (Maria buys a book and reads *her) participants were likely using María (feminine singular) as the antecedent rather than un libro (masculine singular). Less commonly, the participants produced only a few errors using either an indirect, indistinguishable or reflexive pronoun. While still in error, these answers showed that these learners recognized a need for a pronoun and demonstrated knowledge of correct pronoun placement. This is important to note because out of the 816 answers in this study, pronouns were only used $11 \%$ of the time, indicating that, in general, these learners did not see a need to use the direct object pronouns in their responses.

When looking at where errors occurred, it was shown that the majority of the errors happened during the sentence completion task, which accounted for $72.73 \%$ of the errors (16 out of 22). Consequently $27.27 \%$ of the errors (6 out of 22 ) occurred in the question task. For both tasks, the error-type pattern was repeated with position being the most common error.

\section{Conclusion}

Returning to the first research question, for each approach, is there a significant level of improvement in direct object pronoun production following instruction? The answer is no. There is only a significant level of improvement seen for the sentence completion task by the FoF learners who received both formfocused instruction and completed meaning-based activities. This finding suggests that direct object pronoun instruction should include both a focus on the form itself with a brief explanation of grammar and the use of activities which allow students to communicate their own ideas and/or thoughts in the target language while using the pronouns. When further considering the teaching practices used in this study, it is important to also remember the type of corrective feedback that was provided during instruction. The FoF learners received implicit feedback on pronouns only. Such corrections appear to have had a positive impact on the learners, allowing them to better concentrate on the pronouns and their use.

For the second research question, with regard to student improvement in direct object pronoun production, are there any significant differences seen between the three teaching methods employed? The answer is yes, there was a significant difference seen between the FoF group and the FoM group, in favor of the FoF group for the sentence completion task. This is a key result 
because it supports the finding that meaning-based instruction on its own does not appear to be sufficient for learners to make progress in using direct object pronouns (Lightbown \& Spada, 1990; Doughty \& Varela, 1998; Han, 2002; Lyster, 2004; Spada, Lightbown, \& White, 2005; Grim, 2008; Pishghadam, Khodadady, \& Rad, 2011). In comparing FoF to more traditional FoFS approach, a significant difference was not found. It may be argued however, that FoF appears to be a better choice, since those learners were able to make significant improvement and the FoFS learners were not. The more prudent response though is that additional research into the differences between these two approaches for teaching direct object pronouns is warranted.

Finally, given that the posttest showed a low use of pronouns for all learners, the results suggest that beginning learners are in need of a longer period of instruction in order to show more target-like use of the direct object pronouns. Although formfocused instruction was shown to be effective in facilitating learners with the production of direct object pronouns, the levels of improvement that were reached were not comparable to target-like use. Additional investigations of classroom instruction of Spanish direct object pronouns will be beneficial in the overall understanding of how learners acquire the direct object pronouns and what instructional approaches are most beneficial for that acquisition.

\section{Acknowledgements}

I wish to thank Dr. Gillian Lord and Dr. Joaquim Camps for their guidance and assistance with this project, Mr. David Nolen for participating as an instructor, and the students who elected to participate in this study. I also thank the anonymous reviewers for their time and feedback.

\section{REFERENCES}

Camps, J. (1997). Attention to form and meaning in second language acquisition: Object clitic pronouns in Spanish. Doctoral Dissertation, Washington, DC: Georgetown University.

Camps, J. (2003). Concurrent and retrospective verbal reports as tools to better understand the role of attention in second language tasks. International Journal of Applied Linguistics, 13, 201-221.

http://dx.doi.org/10.1111/1473-4192.00044

Doughty, C., \& Varela, E. (1998). Communicative focus on form. In C. Doughty, \& J. Williams (Eds.), Focus on form in classroom second language acquisition (pp. 114-138). Cambridge: Cambridge University Press.

Doughty, C., \& Williams, J. (1998). Pedagogical choices in focus on form. In C. Doughty, \& J. Williams (Eds.), Focus on form in classroom second language acquisition (pp. 197-261). Cambridge: Cambridge University Press.

Ellis, R., Basturkmen, H., \& Loewen, S. (2001). Preemptive focus on form in the ESL classroom. TESOL Quarterly, 35, 407-432. http://dx.doi.org/10.2307/3588029

Grim, F. (2008). Integrating focus on form in L2 content-enriched instruction lessons. Foreign Language Annals, 41, 321-346. http://dx.doi.org/10.1111/j.1944-9720.2008.tb03295.x

Han, Z. (2002) A study of the impact of recasts on tense consistency in L2 output. TESOL Quarterly, 36, 543-572. http://dx.doi.org/10.2307/3588240

Harley, B., \& Swain, M. (1984). The interlanguage of immersion and its implications for second language teaching. In A. Davies, C. Criper, \& A. P. R. Howatt (Eds.), Interlanguage (pp. 291-311). Edinburgh: Edinburgh University Press.

Haspelmath, M. (2002). Understanding morphology. Oxford: Oxford
University Press.

Houston, T. (1997). Sentence processing in Spanish as a second language: A study of word order and background knowledge. In W. R. Glass, \& A. T. Pérez-Leroux (Eds.), Contemporary perspectives on the acquisition of Spanish, vol. 2: Production, processing and comprehension (pp. 123-134). Somerville, MA: Cascadilla Press.

Howatt, A. P. R. (1987). From structural to communicative. Annual Review of Applied Linguistics, 8, 14-29. http://dx.doi.org/10.1017/S0267190500000994

Lee, J. (2003). Cognitive and linguistic perspectives on the acquisition of object pronouns in Spanish as a second language. In B. Lafford, \& R. Salaberry (Eds.), Spanish second language acquisition state of the science (pp. 98-129). Washington, DC: Georgetown University Press.

Lightbown, P. (1998). The importance of timing in focus on form. In C. Doughty, \& J. Williams (Eds.), Focus on form in classroom second language acquisition (pp. 177-196). Cambridge: Cambridge University Press.

Lightbown, P., \& Spada, N. (1990). Focus on form and corrective feedback in communicative language teaching: Effects on second language learning. Studies in Second Language Acquisition, 12, 429448. http://dx.doi.org/10.1017/S0272263100009517

Long, M. H. (1991). Focus on form: A design feature in language teaching methodology. In K. De Bot, R. Ginsberg, \& C. Kramsch (Eds.), Foreign language research in cross-cultural perspective (pp. 39-52). Amsterdam/Philadelphia: John Benjamins.

Long, M. H., \& Robinson, P. (1998). Focus on form: Theory, research, and practice. In C. Doughty, \& J. Williams (Eds.), Focus on form in classroom second language acquisition (pp. 15-41). Cambridge: Cambridge University Press.

Lyster, R. (2004). Differential effects of prompts and recasts in formfocused instruction. Studies in Second Language Acquisition, 26, 399-432. http://dx.doi.org/10.1017/S0272263104263021

Omaggio Hadley, A. (2001). Teaching language in context (pp. 116118). Boston, MA: Heinle \& Heinle.

Pishghadam, R., Khodadady, E., \& Rad, N. D. (2011). The effect of form versus meaning-focused tasks on the development of collocations among Iranian intermediate EFL learners. English Language Teaching, 4, 180-189. http://dx.doi.org/10.5539/elt.v4n2p180

Qin, J. (2008). The effect of processing instruction and dictogloss tasks on acquisition of the English passive voice. Language Teaching Research, 12, 61-82. http://dx.doi.org/10.1177/1362168807084494

Rahimpour, M., Salimi, A., \& Farrokhi, F. (2012). The effect of intensive and extensive focus on form on EFL learners' written accuracy. Theory and Practice in Language Studies, 2, 2277-2283. http://dx.doi.org/10.4304/tpls.2.11.2277-2283

Saeidi, M., Zaferanieh, E., \& Shatery, H. (2012). On the effects of focus on form, focus on meaning, and focus on forms on learners' vocabulary learning in ESP context. English Language Teaching, 5, 72-79. http://dx.doi.org/10.5539/elt.v5n10p72

Schmidt, R. (1990). The role of consciousness in second language learning. Applied Linguistics, 11, 17-46. http://dx.doi.org/10.1093/applin/11.2.129

Sheen, R. (2005). Focus on forms as a means of improving accurate oral production. In A. Housen, \& M. Pierrard (Eds.), Investigations in instructed second language acquisition (pp. 271-310). Berlin: Mouton de Gruyter. http://dx.doi.org/10.1515/9783110197372.2.271

Spada, N., Lightbown, P., \& White, J. (2005). The importance of form/meaning mappings in explicit form-focused instruction. In A. Housen, \& M. Pierrard (Eds.), Investigations in instructed second language acquisition (pp. 199-234). Berlin: Mouton de Gruyter. http://dx.doi.org/10.1515/9783110197372.2.199

Swain, M. (1985). Communicative competence: Some rules of comprehensible input and comprehensible output in its development. In S. Gass, \& C. Madden (Eds.), Input in second language acquisition (pp. 235-253). Rowley, MA: Newbury House.

Toth, P. (2000). The interaction of instruction and learner-internal factors in the acquisition of L2 morphosyntax. Studies in Second Language Acquisition, 22, 169-208.

http://dx.doi.org/10.1017/S0272263100002023

VanPatten, B. (1983). Processing strategies in second language acqui- 


\section{L. D’AMICO}

sition. Doctoral Dissertation, Austin, TX: University of Texas at Austin.

VanPatten, B. (1984). Learners' comprehension of clitic pronouns: More evidence for a word order strategy. Hispanic Linguistics, 1, 57-67.

VanPatten, B. (1993). Grammar teaching for the acquisition-rich classroom. Foreign Language Annals, 26, 435-450. http://dx.doi.org/10.1111/j.1944-9720.1993.tb01179.x

VanPatten, B. (1996). Input processing and grammar instruction: Theory and research. Norwood, NJ: Ablex.

VanPatten, B., \& Cadierno, T. (1993). Explicit instruction and input processing. Studies in Second Language Acquisition, 15, 225-241.

http://dx.doi.org/10.1017/S0272263100011979

VanPatten, B., \& Fernández, C. (2004) The long-term effects of proc- essing instruction. In B. VanPatten (Ed.), Processing instruction theory, research, and commentary. (pp. 273-289). Mahwah, NJ: L. Erlbaum Associates.

VanPatten, B., \& Houston, T. (1998). Contextual effects in processing L2 input sentences. Spanish Applied Linguistics, 2, 53-70.

VanPatten, B., \& Oikkenon, S. (1996). Explanation versus structured input in processing instruction. Studies in Second Language Acquisition, 18, 495-510. http://dx.doi.org/10.1017/S0272263100015394

VanPatten, B., \& Sanz, C. (1995). From input to output: processing instruction and communicative tasks. In F. R. Eckman, D. Highland, P. W. Lee, J. Milcham, \& R. Rutkowski Weber (Eds.), Second language acquisition theory and pedagogy (pp. 169-185). Hillsdale, NJ: Erlbaum. 